\title{
O professor de língua portuguesa no contexto atual: desafios e avanços
}

\author{
Manoel Guilherme de FREITAS ${ }^{1}$ \\ Maria do Socorro Maia Fernandes BARBOSA ${ }^{2}$
}

Resumo: Este artigo objetiva refletir sobre o ensino de língua portuguesa no contexto atual das escolas públicas estaduais do município de Pau dos Ferros - RN, a partir da pesquisa do Mestrado Acadêmico em Letras, do Programa de Pós-Graduação em Letras - PPGL, da Universidade do Estado do Rio Grande do Norte - UERN. Para tanto, referenciaremos Marcuschi (2008), Dioniso (2002), Brandão \& Vieira (2010), Travaglia (2001), Neves (2002), Bakhtin (1995), Bauman (2008), dentre outros, documentos oficiais PCNs (1997). Logo, exporemos como o ensino está ligado ao Estruturalismo linguístico, embora já existam professores que tem no Funcionalismo Linguístico e a corrente linguística adotada cotidianamente nas salas de aula. Dessa forma, o ensino de LP convive com uma fusão de concepções, prejudicando, assim, o avanço, haja vista que os professores não deveriam mais concebê-lo enquanto cópia, mecanização, fora de um contexto real de uso dessa língua. Assim sendo, o professor deverá buscar as transformações necessárias à formação de um leitor critico, a partir do uso dos gêneros textuais diversos, para que a sala de aula possa ser um habitat de troca, de interação entre os alunos-sujeitos, porém jamais como pretexto para exploração de uma gramática ideal, que não satisfaz à realidade dos alunos. Portanto, deve ser num contexto plural, levando em consideração que a língua não é homogênea e deve estar à disposição dos falantes nativos para defender pontos de vista, criticar, opinar, expressar coerentemente dentro do contexto de uso.

Palavras - chave: Língua portuguesa. Estruturalismo linguístico. Funcionalismo linguístico. Professores. Contexto atual.

Abstract: This article reflects on the teaching of the Portuguese language in the current context of public schools in the city of Pau Irons-RN, from the Academic Research Master of Arts, the Graduate Program in Literature PPGL, the University of Rio Grande do Norte-UERN. Therefore, referenciaremos Marcuschi (2008), Dionysus (2002), Brandão \& Vieira (2010), Travaglia (2001), Neves (2002), Bakhtin (1995), Bauman (2008), among others, official documents PCNs (1997). Soon, we will expose how teaching is linked to linguistic structuralism, although there are teachers who have the Language Functionalism and current linguistic adopted routinely in classrooms. Thus, teaching LP coexists with a fusion of concepts, and thus impair the advance, considering that teachers should no longer think of it as copying, mechanization, out of a real context of use that language. Therefore, the teacher should seek the necessary changes to the formation of a critical reader, from the use of different genres, so that the classroom can be a habitat of exchange interaction between the student-subject, but never as pretext for ideal operation of a grammar, which does not meet the reality of students. So there must be a plural context, taking into account that the language is not homogeneous and should be available to the native speakers to defend points of view, criticize, opine, express coherently within the context of use.

Keywords: Portuguese Language. Linguistic structuralism. Linguistic functionalism. Teachers, The current context.

\section{Introdução}

\footnotetext{
${ }^{1}$ Mestre em Texto e Discurso pela Universidade do Estado do Rio Grande do Norte - PPGL/UERN. Professor de educação básica da SEEC/RN. E-mail: mguilhermedefreitas@ hotmail.com.

2 Prof $^{a}$ Dr $^{a}$ Adjunta I Maria do Socorro Maria Fernandes Barbosa do Departamento de Letras do Campus Avançado Professora "Maria Elisa de Albuquerque Maia", CAMEAM, da Universidade do Estado do Rio Grande do Norte UERN. E-mail: socorromaia_uern@ig.com.br.
} 
Não é fácil ser professor no contexto plural, pois exige conhecimento teórico- prático, bem como estratégias diversificadas de leitura e de escrita que, na maioria das vezes, extrapolam o habitat social de sala de aula, ou seja, por mais que o professor tente uniformizar o ensino no sentido de uma aprendizagem significativa para todos, existirá sempre a indiferença, a rejeição à prática escolar in loco da sala de aula.

Contudo, este professor não pode omitir-se diante dos grandes desafios que existem na sociedade contemporânea, principalmente enquanto indivíduo capaz de transformá-la a partir de uma pedagogia que não leve ao "silenciosamento, fechamento" (MUSSALIN, 2005), no sentido de erradicar as injustiças, as diferenças que existem de modo conflituoso no seio escolar. Dessa forma, este pode contribuir bastante para a formação dos alunos, principalmente através de valores, de hábitos, de atitudes essências à consciência crítica dos discentes, além de despertá-los para a sua cidadania.

Com efeito, urge a necessidade de abdicar de dogmas universalizantes existentes no ensino, para que possamos atender às necessidades imediatas e reais dos alunos. Assim sendo, o pilar educativo "aprender a aprender" Passa a ser substituído por outros modernos, a saber: "aprender a ser", "aprender a fazer", "aprender a viver", "aprender a conhecer" (PERRENOUD, 2000), ou seja, o conhecimento deve ser socializado, interagido, trocado entre os sujeitos envolvidos no processo de ensino e aprendizagem, jamais como algo monótono, estanque, em que a figura do professor protagonista ${ }^{3}$ sobressai sobre os demais indivíduos.

Dessa forma, o aluno deve ser visto como sujeito ativo, que busca sua identidade. Para tanto, precisa que os professores rompam com modelos estanques e ultrapassados como: mecanização e/ou "decoreba", anotações de resumos de textos, exposição, que não seja a dialogada em sala de aula. Enfim, que a sala de aula seja um local de interlocução, de troca, onde haja a interpretação e reinterpretação da realidade social dos sujeitos.

Noutros termos, tanto o diálogo quanto a interlocução possibilitam a construção de sentidos diversos, através da significação no ensino. Assim sendo, levam os docentes de Língua Portuguesa (doravante LP) a pensarem o ensino numa dimensão superior, ou seja, social, histórica essencial às transformações de seu tempo. Sobre língua Beth (1997, p.7) apud ROJO, 2002, p.17) afirma:

\footnotetext{
${ }^{3}$ Professor tradicional, ou seja, que a borda o ensino de Língua Portuguesa pelo viés da gramática.
} 
"Língua é um sistema de signos específico, histórico e social, que possibilita ao homem significar o mundo e a sociedade. Assim, aprendê-la é aprender não somente as palavras é saber combiná-las em expressões complexas, mas aprender pragmaticamente os seus significados e, com eles, os modos pelos quais as pessoas entendem e interpretam a realidade e a si mesmas" (BETH 1997, p. 7, apud ROJO, 2002, p. 17).

Portanto, a língua não limita apenas as combinações de letras, sílabas ou palavras. Logo, é muito mais do que isso; é, acima de tudo, construir sentidos, bem como saber pragmaticamente os modos pelos quais essa língua funciona e interage com os interlocutores via comunicação humana.

Assim sendo, esse conhecimento pragmático e social da língua é fundamental para o professor de LP no que tange ao processo de ensino e aprendizagem, já que este deve ser construído cotidianamente na interação dos aprendizes na sala de aula, senão também fora dela, nas diversas situações pelas quais passam o indivíduo. Jamais como imposição e/ou improvisação, que remonta ao Estruturalismo Linguístico já que este tem recebido críticas pelo fato de não levar em consideração os fatores sociais e externos da linguagem.

Contudo, hoje, o perfil de sociedade e de homem exige novos paradigmas científicos voltados para a produção do conhecimento. Convictos dessa asserção, justificamos que discorrer sobre o papel do professor na sociedade contemporânea é oportuno, porque em tempos de globalização da cultura, da indústria cultural, de uma sociedade midiatizada, da preferência por valores estereotipados, da despolitização social, do preconceito étnico e linguístico, da cultuação do corpo, das minorias rotuladas ou etiquetadas de negros, lésbicas, gays, da cultura Mcdonalds, da ideia de planetarização dentre outras realidades afins, parece ser imperioso discorrer à miude sobre a formação do professor versus prática profissional do professor de língua portuguesa da rede básica, na perspectiva de que as mudanças identitárias e a efervescência histórico-econômica e político-cultural não sejam vistas tão somente enquanto práticas sociais desterritorializadas.

Logo, é condicionante que o professor usufrua deste conhecimento científico para compreender as mudanças conjunturais de análise política e social na perspectiva de trabalhar, a contento, a formação educacional dos sujeitos-aprendizes da sociedade chamada contemporânea ou pós-moderna (JAMESON, 2000).

Face ao exposto, a questão que se coloca é o professor tem conhecimento científico, competência formativa transdisciplinar, habilidades e estratégias metodológicas; para lidar 
com o sujeito e o objeto do conhecimento da sociedade chamada contemporânea ou pósmoderna? Como vem sendo urdida a organização escolar brasileira em todos os níveis de ensino? Como se avalia a formação intelectual do profissional de Letras? Quais as possibilidades de conhecimento que o professor trabalha? Qual a concepção de aprendizagem que o professor assume? Os currículos e os conteúdos programáticos atendem a realidade atual dos sujeitos-aprendizes, ou retém o aprendizado? Que conhecimento, competência e domínio pedagógico formativo o professor de língua portuguesa precisa ter; no atual contexto social?

Responder a essas interrogações é preciso, é urgente, haja vista a necessidade de se repensar o processo educacional brasileiro, proposto há décadas. Dito de outro modo, rever posturas e experiências formativas, que não se coadunam ou não atendem a sociedade que aí está, é uma prioridade ímpar, pois "o sucesso na vida (e assim a racionalidade) dos homens e mulheres pós-modernos depende da velocidade com que conseguem se livrar de hábitos antigos, mais do que da rapidez com que adquirem novos" (BAUMAN, 2008, p. 161).

\section{O professor de língua portuguesa no contexto atual}

Como deve ser o professor de língua portuguesa atualmente? Será que ele apenas reproduzirá a ideologia do Positivismo ${ }^{45}$, Estruturalismo Linguístico? Ou conceberá o ensino como um objeto de ensino dinâmico, capaz de intervir significativamente na formação de alunos-leitores? Ou seja, o interacionismo. Afinal, qual é a relevância que tem o ensino na formação da vida dos alunos? Sobre este ensino, concordamos com Brandão \& Vieira (2010, p. 9-10), quando princípios fundamentais à prática didático-pedagógica:

“(i) O objetivo maior do ensino de Língua Portuguesa é desenvolver a competência de leitura e produção textual; (ii) a unidade textual em toda a sua diversidade de tipos e gêneros, nos diferentes registros, variedades, modalidades, consoantes as possíveis situações sociocomunicativas - deve ser o ponto de partida e de chegada das aulas de Português; e, (iii) os elementos de natureza formal relativos aos diferentes níveis de gramática são essenciais para a construção do texto" (BRANDÃO, 2010, p. 9-10).

\footnotetext{
${ }^{4}$ Corrente cientifica-filosófica da metade do séc. XIX, que tentou explicar a linguagem a partir lógica, do racional.
} 
Com efeito, o professor não deve tratar a língua como homogênea. Nesse sentido, Brandão \& Vieira (2007, p. 21) comentam que "a Língua Portuguesa não é homogênea, como nenhuma língua é, mas sim heterogênea plural e polarizada, se considerar o todo do português brasileiro e não apenas a idealizada norma padrão".

Nesse sentido, o professor deverá oportunizar experiências com a linguagem, onde os alunos possam interagir/dialogar, fazendo uso da modalidade oral da língua, através de estratégias de leituras e de escrita recorrentes e consistentes para a consecução de tais objetivos, que são a interlocução e/ou interação entre os alunos. Para tanto, o uso do texto na sala de aula deverá ser inovador, diferenciado, atendendo às expectativas dos alunos, bem como constante e de maneira contextualizado, significativo.

Então, por que o professor deve desconsiderar os usos plurais da língua? Fala-se diferente no bar, no campo, na rua, pois seria um equívoco pensá-la como algo uniforme. Logo, o professor pode oferecer outras variantes, que não somente a norma culta, para que possa fazer a diferença na sala de aula. Diante disto, é essencial que abra a "escola à pluralidade dos discursos" (TRAVAGLIA, 2001, p.41). Ainda nesse sentido, o autor reforça:

\begin{abstract}
“A nossa sociedade tem uma longa tradição em considerara variação numa escala valorativa, às vezes até moral, que leva a tachar os usos característicos de cada variedade como certos ou errados, aceitáveis ou inaceitáveis, pitorescos, cômicos, etc. Todavia se acredita que em diferentes tipos de situação tem-se ou deve-se usar a língua de modos variados, não há por que, realizar as atividades de ensino/aprendizagem da língua materna, insistir no trabalho apenas com uma das variedades, à norma culta" (TRAVAGLIA, 2001, p.41).
\end{abstract}

Conforme o autor, a escola tem esse poder de ajudar os alunos na obtenção da norma culta, pois se ela não fizer isto, quem fará? Todavia, a escola tem a obrigação de oferecer outras possibilidades linguagens e/ou variações aos alunos, ou seja, modos de uso da língua, de dependendo do contexto, da situação, dos usuários, da faixa etária, dentre outros enfoques. Ainda cerda do autor, há basicamente dois grandes tipos de variações, a saber: "variação dialetal e variação e registro", cada um com seus subtipos específicos.

Nesse sentido, o contexto atual do ensino de LP exige que o professor tenha conhecimento desta realidade de ensino, principalmente vendo a fala como contraparte da escrita da língua, de sorte que a interação, a comunicação ocorram face a face nos falantes nativos. Para tanto, é preferível que se parta das noções do outro, do sujeito, do discurso e do 
texto, consolidados no uso de gêneros textuais diversificados e significativos nas salas de aula.

Logo, o professor que faz a diferença na sala de aula cotidianamente, possibilitará a formação, promoção e ascensão social do seu aluno através da leitura e da escrita. Para tanto, é fundamental que os alunos tenham acesso ao código linguístico da língua escrito ou falado. Pois, é partir dele que o indivíduo passa a ter acesso ao sistema de signos e atribuirá valores e significações. Assim sendo, descobre o mundo e a sua realidade circundante.

Neste âmbito, o professor deve atuar no ensino de língua portuguesa transpondo o significado literal do texto e indo para o contexto, à enunciação, à vida dos alunos, exigindo, cada vez mais, a ruptura com o passado e a incorporação do novo através dos fatores externos da linguagem consubstanciados nas condições materiais e históricas que medeiam a existência humana, sem, no entanto, limitar e/ou bitolar os aspectos micro ou macro da língua, antes, promovendo a junção deles.

Dessa forma, a concepção pedagógica do professor e o ensino de língua portuguesa passam por mudanças significativas oriundas; principalmente da incorporação da Gramática do Texto e das Teorias do Discurso; ajudando assim, na busca por novos objetivos voltados à formação do aluno sujeito, possibilitando-o expressar criticamente suas opiniões, pensamentos, defender seu ponto de vista. Enfim, interagir sócio e discursivamente pelo viés da língua.

Apesar da ruptura da tradição escolar da gramática, o ensino nem sempre teve a conotação plural nas salas de aula de Língua Portuguesa, contrariando assim, o que pregoam os documentos oficiais, os livros e as revistas especializadas no assunto e, principalmente, as escolas. Logo, o professor in loco de sala de aula, não deverá conceber "a língua enquanto código linguístico" (CEREJA \& MAGALHÃES, 2005). Contudo, enquanto construção de novos sentidos, voltados para a formação de "um leitor eficiente e competente" (KOCH \& ELIAS, 2010). Noutros termos, muitos de tais professores transmitem os conteúdos como se fosse verdade absoluta, através de modelos estruturais de análise linguística, sem nenhuma vinculação com a realidade social dos alunos.

De acordo com este pensar, o ensino era alimentado através da estrutura linguística/da língua, já que partiam sempre de pares mínimos de enunciados, da oposição das funções, das categorias gramaticais, segundo a visão saussuriana, a partir de suas famosas dicotomias (SAUSSURE, 1996). Então, a ênfase recaía sobre o sistema, a forma, já que pouca atenção 
era dada à leitura, à compreensão textual e a produção de texto. Esse modelo, mesmo ultrapassado, ainda resiste; por parte de alguns profissionais que reproduzem e alimentam todo um pensar convencional e homogêneo, alheios às mudanças e pretensões de novos sentidos.

Dessa forma, professores remanescentes das décadas de 80 e 90 incorporaram o modelo mecanicista às salas de aula. Afigura do professor é inquestionável neste modelo pedagógico, que é disciplinador e estruturalista, já que reproduz o manual da gramática tradicional como o único possível para aprendizagem dos alunos. Contudo, sem levar em consideração o fracasso escolar da maioria dos alunos. Mas, na década de 90 e nos anos 2000, começam aparecer novas concepções, correntes linguísticas e/ou filosóficas voltadas à superação dos paradigmas estruturais dando diferentes rumos à língua a partir do interacionismo linguístico. De acordo com esse pensar, Neves (2002, p. 153), reforça:

\footnotetext{
"A palavra-chave da linguística bakhtiniana é diálogo. Só existe língua onde houver possibilidade de interação social, dialogal. A língua não reside na mente do falante, nem é um sistema abstrato que paira acima das condições sociais. A língua é um trabalho empreendido conjuntamente pelos falantes, é uma atividade social, enunciação" (NEVES, 2002, p.153).
}

Portanto, disto resulta uma certeza: as novas teorias e concepções de texto e de ensino, e consequentemente de sujeito, são necessárias para que os alunos aspirem, almejem à ascensão social em suas vidas, já que os gêneros textuais têm mostrado que o homem não se comunica por frases soltas, mas por textos, sendo que cada texto encontra-se ancorado em um gênero específico, senão também "é impossível se comunicar verbalmente não ser por algum texto" (DIONÍSIO, 2002. p. 22.).

Dessa forma, o professor pode oferecer um ensino de qualidade, a partir da incorporação do texto nas aulas de língua portuguesa, principalmente através de gêneros textuais diversificados, despertando neles, o hábito e o prazer pela leitura crítica. Para tanto, é preciso que os professores ousem, inovem, estudem, tendo na interação linguística a base de sustentação de sua prática docente.

Nesse sentido, o contexto atual exige que o professor tenha conhecimento desta realidade de ensino, principalmente vendo a fala como contraparte da escrita da língua, de sorte que a interação, a comunicação ocorram face a face nos falantes nativos, desde que se parta das noções do outro, do sujeito, do discurso e do texto, consolidados no uso de gêneros textuais diversificados e significativos nas salas de aula. 
Salientamos, outrossim, que a leitura e a escrita ganham importância na medida em que o texto "é construído sócio e historicamente nas diversas esferas sociais de que o homem participa na sociedade" ( FREITAS ORGS, 2008 p. 9). Dessa forma, não tem como não utilizá-lo para que provoque os efeitos de sentidos desejados, tendo como parâmetros essenciais à leitura, à escrita e à produção textual.

Portanto, é cobrado do professor o domínio linguístico das competências: gramatical ou linguística e a textual (TRAVAGLIA, 2001, p. 17),para que este possa ajudar os alunos no uso adequado das diversas linguagens, como também de acordo com as situações reais e específicas do cotidiano dos discentes de modo que estes usufruam do código linguístico para suas necessidades comunicativas, adequando-as ao registro, às normas de convenções dessa escrita.

\section{Os gêneros textuais no ensino de Língua Portuguesa}

Os gêneros textuais são uma realidade e necessidade no ensino, pois toda ação humana se dá em algum gênero textual (MARCUSCHI, 2008), assim como todo o texto, encontra-se ancorado em algum dos gêneros textuais, sejam literários ou não. No início, foram poucos na Grécia Antiga e remontavam a Platão e a Aristóteles. Sobre os gêneros, Dionísio (2002, p. 19) firma:

\footnotetext{
"Uma simples observação histórica do surgimento dos gêneros revela que, numa primeira fase, povos de cultura essencialmente oral desenvolveram um conjunto limitado de gêneros. Após a invenção da escrita alfabética por voltado século VII A.C, multiplicam-se os gêneros, surgindo os típicos da escrita. Numa terceira fase, a partir do século XV, os gêneros expandiram-se com o florescimento da cultura impressa para na fase intermediária de industrialização iniciada no século XVIII, dar início a uma grande ampliação" (DIONÍSIO, 2002, p.19).
}

Portanto, os gêneros surgiram e/ou surgem ancorados às necessidades sociais, já que se prestam às mais variadas formas de expressão e de comunicação entre os indivíduos. Logo, quanto mais desenvolvida for à sociedade, mais possibilidade terá de aparecer novos gêneros textuais diversificados. Dessa forma, eles são uma necessidade humana, pois o homem se comunica sempre através de gêneros.

Logo, eles são plásticos, dinâmicos e se encontram nas diversas esferas socais de comunicação e socialização (BAKHTIN, 2002). Neste contexto, não há como não partir do 
ensino sem sua presença, tanto pela sua dinamicidade quanto comodidade. Ainda sobre os gêneros textuais, Marcuschi (2008, p.147) reforça:

\begin{abstract}
“Atualmente, a noção de gênero já não mais se vincula apenas à literatura, como lembra Swales (1990:33), ao dizer que hoje, gênero é facilmente usado para referir uma categoria distintiva do discurso de qualquer tipo, falado ou escrito com ou sem aspirações literárias. É assim que seus a noção gênero textual" (MARCUSCHI, 2008, p.147).
\end{abstract}

Dessa forma, a classificação dos gêneros a partir da literatura não contemplava à diversidade de textos que existem na modernidade, além de não atenderem à realidade social dos alunos, já que há um leque muito grande de novos gêneros textuais existentes no cotidiano. Uma vez que os clássicos da literatura não atendem às necessidades linguísticas atuais, a tradição retórica ficou em segundo plano, face às teorias da enunciação.

Noutros termos, os gêneros textuais possibilitaram ao ensino de língua portuguesa mais operacionalidade e consistência, principalmente se levar em consideração às "práticas de leitura, prática de produção de textos, que, por sua vez, se desdobra em "Aspectos discursivos" e “Aspectos notacionais", (PCN, 1997 p. 44), já que se voltam à interação, haja vista que, em décadas anteriores, era impossível.

Consoante ao modelo pedagógico de ensino de LP das décadas de 1970 a 1980, o Estruturalismo linguístico impôs seu modo de pensar e de normatizar o estudo de língua, através do mecanicismo, deixando-o enfadonho e retrógrado. Ainda assim, existiram alguns gêneros abordados, a saber: o bilhete, a carta, o recado, o texto oficial, embora sua utilização fosse restrita e esporadicamente estudada em ocasiões especiais, somente para atender às necessidades imediatas.

No entanto, após o advento de novas tecnologias e das concepções modernas de linguagem: a sociointeração e a sociodiscursiva, os gêneros ganharam em dimensão e diversidade, daí poder associá-los às situações práticas de linguagens do cotidiano, até por que o homem não se comunica a não ser por meio de textos. Nesse sentido, Dionísio (2002, p. 19) reforça:

"Surgem emparelhados a necessidades e atividades sócio-culturais, bem como na relação com inovações tecnológicas, o que é facilmente perceptível ao se considerar a quantidade de gêneros textuais hoje existentes em relação a sociedades anteriores à comunicação escrita" (DIONÍSIO, 2002, p.19). 
Ainda nesse pensar, podemos dizer que eles são múltiplos, heterogêneos e não estanques, no dizer de Bathia (1997, p. 629) apud Marcuschi (2008, p. 417), os gêneros são "um conceito que achou seu tempo". Assim sendo, a melhoria do ensino de LP, passa, necessariamente, pelo uso dos gêneros textuais, já que estes, se utilizados adequadamente nas aulas, poderão provocar efeitos de sentido diferentes nos discentes, dada a sua dinamicidade e pluralidade existentes. Tal diversidade ocorre nos seus tipos, aspectos formais e/ou estéticos, discursivos, níveis de formalidade, bem como registros.

\subsection{Tipos de textos e gêneros de textos: há diferenças?}

O que era, antes, estudado isoladamente, fora de uma situação real de aprendizagem, distanciado do lócus dos alunos, hoje, não tem sentido ser estudados separados: ou seja, tipos de textos e gêneros de textos. Pois, quando se parte de um texto como unidade básica de ensino, consequentemente as sequências linguísticas aparecem ancoradas dentro do gênero em estudo.

Modernamente, fala-se em intertextualidade tipológica, que é um gênero com a presença de vários tipos de textos; (entendido como: narração, descrição, texto expositivoargumentativo, informativo, injuntivo) e a intergenericidade de gêneros que é, um gênero com o formato de outro, algo extremamente comum na linguagem da publicidade.

Portanto, no ensino de LP não se deve partir de uma sequência linguística isolada, mas de gêneros textuais, sendo que dentro deles podem ser explorados os tipos de textos inerentes, com ênfase no tipo predominante. Então, não tem mais como ensinar tópicos linguísticos fora de um contexto real de aprendizagem, daí o uso da gramática normativa não mais ter mais ter a aplicabilidade exclusiva no ensino. Assim sendo, a norma culta deverá ser ensinada a partir do uso social de que se faz dela e, jamais, fora de uma situação específica de aprendizagem dos discentes.

Por fim, há diferença com relação ao ensino de LP, se comparado há décadas anteriores, principalmente a partir da dimensão social e discursiva que se têm dado à língua, já que esta deverá estar consolidada nos gêneros discursivos bakthinianos, consequentemente voltados à comunicação e interação dos sujeitos, favorecendo assim, à formação crítica do aluno sendo, principalmente sujeito do processo. Competência essa que impossível, quando o ensino foi centrado na transcrição e mecanização de regras de uma gramática ideal que, na 
realidade, não tendia às expectativas dos falantes nativos, já que não existia a interlocução destes no processo ensino aprendizagem dos alunos.

\section{Considerações finais}

O ensino de gramática é fundamental para a ascensão social dos discentes, mas desde que seja utilizado a partir de situações reais no processo de ensino aprendizagem, ou seja, no uso específico da enunciação viva dos falantes, jamais como pretexto para uso descritivo das regras da gramática descritiva e/ou normativa,

Nesse sentido, o que não faltam são situações que os professores podem tratar a gramática, partindo do uso funcional dela, de forma sistemática e assídua. Ocorre que, às vezes, o professor pode ter conhecimento limitado da norma culta e acaba não sabendo explorar essa gramática como deveria ser nas aulas de Língua Portuguesa.

Dessa forma, ela não deve ser o centro do processo de ensino aprendizagem, mas a ferramenta de apoio de todo professor, para que em situações reais de aprendizagem, possa adequar o uso ao contexto linguístico dos alunos, pois este deve centrar-se no uso dos gêneros textuais, como elementos portadores de vários sentidos, bem como por serem plásticos dinâmicos e recorrentes.

Com efeito, lidar com o texto, o discurso e os gêneros textuais é uma ação condicionante para a melhoria do ensino de Língua Portuguesa. Ainda assim, há resistência por parte de alguns professores, já que estes não têm o domínio teórico e técnico de como operacioná-los e transformar velhos dogmas, ainda presentes no habitat escolar.

Neste contexto, o ensino que vise à qualidade não deve menosprezar a interlocução, a interação entre os sujeitos envolvidos na construção do processo ensino aprendizagem, através de uma pedagogia de gramática que não seja estanque, portanto distante do lócus dos alunos, pois é impossível fazer a diferença no ensino partindo de frases soltas, de fragmentos fora de um contexto real e social dos falantes.

Dessa forma, pensar o uso da gramática numa perspectiva funcionalista é oferecer um ensino crítico de gramática, no qual os alunos possam pensar racionalmente e criticamente sobre os usos da língua, a partir das subjetividades, intencionalidades, registros, modalidades. E isso não pode ficar distorcido, quando se trata de ensino de LP, pois a gramática pode ser utilizada perfeitamente durante as aulas, no entanto é essencial que se redimensione e dê sentido a sua utilização. 
Com efeito, em se tratando do ensino de Língua Portuguesa numa perspectiva sociointerativa e/ou discursiva, a gramática aparece quando há necessidade de fixação de uma regra, ou mesmo para diferenciar de outros usos existentes. Ainda assim, não se pode menosprezá-la, tendo em vista que o domínio da variante culta da Língua Portuguesa passa pelo seu acesso. Logo, o que precisa mudar, urgentemente, são as políticas de formação de professores, bem como os mitos de que a gramática deve ser a protagonista do ensino de LP.

Portanto, o professor de Língua Portuguesa deve ser dinâmico, atual para que possa fazer as mudanças necessárias às transformações desejadas. Para tanto, requer novos métodos e estratégias voltadas à realização desses propósitos, dessa forma passa pelo uso dos gêneros textuais no ensino, bem como a prática de leitura e escrita como ferramentas essenciais dessas mudanças.

\section{Referências}

BAKHTIN, Mikhail. (Volochínov). Estética da criação verbal. São Paulo: Martins Fontes, 1992.

. Marxismo e filosofia da linguagem. Tradução L. Y. F. V. São Paulo: Hucitec, 1995.

BRASIL, Ministério da Educação. Secretaria de Educação Fundamental. PCN: terceiro e quarto ciclos do Ensino Fundamental - Língua Portuguesa, 1997.

BAUMAN, Zygmunt. A vida para o consumo. Rio de Janeiro: Zahar, 2008.

BAZERMAN, Charles. Gêneros textuais: tipificação e interação. São Paulo, 2008.

BRANDÃO, Sílvia Figueiredo \& VIEIRA, Sílvia Rodrigues (Orgs.). Ensino de gramática: descrição e uso. São Paulo: Contexto, 2007.

CEREJA, William Roberto \& MAGALHÃES, Thereza Cochar. Português: linguagens. 5. ed. São Paulo: Atual, 2005. V.1.

DIONÍSIO, Ângela Paiva (Orgs). Gêneros textuais e ensino. 2. ed. Rio de Janeiro: Lucerna, 2002.

FELDEMANN, Marina Graziela. Formação de professor e escola na contemporaneidade. São Paulo, 2009.

FREITAS, A. C.; RODRIGUES, L. O.; SAMPAIO, M. L. P. (Orgs.). Linguagem, Discurso e Cultura: múltiplos objetos e abordagem: Mossoró: Queima-Bucha, 2008.

KOCH, I. G. V. O texto e a construção de sentido. São Paulo: Contexto, 2002.

.Desvendando os segredos do texto. 5. ed. São Paulo: Cortez, 2006.

LIBÂNEO, José Carlos. Adeus professor, Adeus Professora? Novas exigências educacionais e profissão docente. São Paulo. 2003.

MARCUSCHI, Luiz Antonio. Produção textual, análise de gêneros e compreensão. São Paulo: Parábola, 2008. 
NEVES, Maria Helena de Moura. A gramática: história, teoria e análise, ensino. São Paulo: UNESP, 2002 SAVIANI, D. Educação Brasileira: estrutura e sistema. 9 ed. Campinas, SP: Autores Associados, 2005, p. 2-120.

PERRENOUD, P. Novas competências para ensinar. São Paulo: Artmed, 2000.

TRAVAGLIA, Luiz Carlos. Gramática e interação: uma proposta para o ensino de gramática no $1^{\circ}$ e $2^{\circ}$ graus. São Paulo: Cortez, 2011. 